\title{
On the formation of blue ice on Byrd Glacier, Antarctica
}

\author{
S.R.M. LIGTENBERG, ${ }^{1}$ J.T.M. LENAERTS, ${ }^{1}$ M.R. VAN DEN BROEKE, ${ }^{1}$ T.A. SCAMBOS ${ }^{2}$ \\ ${ }^{1}$ Institute for Marine and Atmospheric Research Utrecht (IMAU), Utrecht University, Utrecht, The Netherlands \\ E-mail: S.R.M.Ligtenberg@uu.nl \\ ${ }^{2}$ National Snow and Ice Data Center (NSIDC), CIRES, University of Colorado, Boulder, Colorado, USA
}

\begin{abstract}
Blue-ice areas (BIAs) cover $\sim 1 \%$ of the East Antarctic ice sheet and are visual evidence of persistent ablation. In these regions, more snow is sublimated and/or eroded than is accumulated. The physical processes driving the formation of BIAs are poorly understood. Here we combine a firndensification model with high-resolution $(5.5 \mathrm{~km})$ maps of surface mass balance and ice velocity to simulate the build-up and removal of a firn layer along an ice flowline passing Byrd Glacier. A BIA is formed once the complete firn layer is removed. Feedback processes, which enhance blue-ice formation through the difference in surface characteristics of snow and ice, are examined using sensitivity simulations. The presence of blue ice on Byrd Glacier is found to be mainly determined by (1) ice velocity, (2) surface mass balance and (3) the characteristics (thickness, mass) of the firn layer prior to entering the ablation area. With a moderate decrease of the surface mass balance, the location and extent of the simulated BIA on Byrd Glacier is found to be in good qualitative agreement with MODIS optical imagery.
\end{abstract}

KEYWORDS: blue ice, glacier ablation phenomena, polar firn, snow/ice-surface processes, surface mass budget

\section{INTRODUCTION}

The Antarctic ice sheet (AIS) is almost completely covered by a $50-150 \mathrm{~m}$ thick layer of firn, the transitional phase of snow to ice (Ligtenberg and others, 2011). In blue-ice areas (BIAs), however, no firn layer exists and glacier ice is exposed at the surface (Bintanja, 1999; Sinisalo and Moore, 2010). Various observational and model studies show that $0.8-1.6 \%$ of the AIS surface can be classified as a BIA (e.g. Winther and others, 2001; Van den Broeke and others, 2006). BIAs experience net ablation, caused by a combination of low precipitation, strong sublimation of drifting and surface snow, erosion of surface snow, and/or melt (Takahashi and others, 1988; Bintanja and Van den Broeke, 1995; Van den Broeke and others, 2006). To some extent, BIAs are self-sustaining; blue ice has a lower surface albedo (0.5-0.6) than snow (0.8-0.9) (Bintanja and Van den Broeke, 1995), leading to more absorbed radiation and higher surface temperatures in summer, enhancing sublimation rates. Also, blue ice is smoother than snow, making it harder to form a continuous snow cover on the surface (Van den Broeke and Bintanja, 1995a).

BIAs were first observed and studied in the 1950s during the Norwegian-British-Swedish Antarctica Expedition in Dronning Maud Land (DML) (e.g. Schytt, 1961). During the following half-century, the main focus of BIA research was geological and paleoclimatological, as the ice at the surface of a BIA can be very old and therefore provides relatively easy access to climate archives. The discovery of numerous meteorites on BIAs further enhanced this interest (Yoshida and others, 1971; Cassidy and others, 1992). Their smooth and hard surfaces also make them potential runways for wheeled aircraft (Swithinbank, 1991). Later, the focus of research shifted more towards the physical properties of BIAs and their surface energy balance (e.g. Bintanja and Van den Broeke, 1995; Van den Broeke and Bintanja, 1995a,b).

BIAs can be mapped using spectral radiation data from satellites, typically by comparing visible bands with a near- or middle-infrared channel (e.g. Winther and others, 2001; Brown and Scambos, 2004; Scambos and others, 2007), or from climate models that simulate the surface mass balance (SMB) (Van den Broeke, 1997; Van den Broeke and others, 2006; Lenaerts and others, 2012a). A larger part of the East Antarctic plateau $(\sim 17 \%)$ is classified as 'windglaze' or 'wind-scour' areas (Scambos and others, 2012; Das and others, 2013), which are characterized by a windswept, smooth surface. The SMB of wind-glaze areas is near zero $\left(-20\right.$ to $\left.+20 \mathrm{~kg} \mathrm{~m}^{-2} \mathrm{a}^{-1}\right)$, and slightly negative for wind-scour regions. However their surfaces still consist of firn instead of glacier ice, which can be explained by the finite residence time in ablation areas, owing to ice flow.

The formation of BIAs can be divided into two main processes: roughly half is classified as wind-induced BIA, while the other half is melt-induced (Winther and others, 2001; Van den Broeke and others, 2006). A wind-induced $\mathrm{BIA}$ is characterized by a smooth, rippled surface where wind divergence leads to snow erosion. In combination with ongoing sublimation, this causes a negative SMB. This BIA type is often observed on the leeward side of a nunatak in the ice sheet (Takahashi and others, 1992; Bintanja, 1999). Firstly, the nunatak blocks or redirects precipitating and drifting snow, so snow does not deposit on the leeward side. Secondly, the rock causes turbulence and wind divergence on its leeward side, leading to more enhanced erosion and sublimation. Thirdly, ice velocity is low around a nunatak, giving the ablation processes time to remove the full firn layer. The horizontal length scale of a wind-induced BIA is related to the height of the nunatak (Takahashi and others, 1992). In DML and other mountainous areas (e.g. the Transantarctic Mountains), numerous wind-induced BIAs are present. In contrast, a melt-induced BIA shows a more irregular surface with depressions and hollows. When meltwater refreezes near the surface, or runs off to lowerlying areas, it can form lakes in surface depressions (Winther and others, 2001). Melt-induced BIAs are often found near 


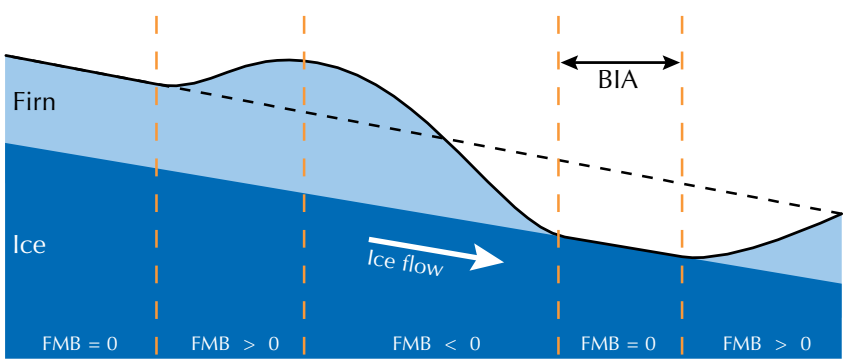

Fig. 1. Schematic representation of an ice column, including a firn layer, along a flowline that flows from the ice divide (left) towards the glacier terminus (right). Orange lines separate regions with different regimes of firn mass balance (FMB), including the blue-ice area $(\mathrm{BIA})$.

the Antarctic coast, where temperatures are high enough to produce significant melt. The largest known area is located on Lambert Glacier and the Amery Ice Shelf, East Antarctica (Yu and others, 2012).

Another BIA classification that can be used is whether the BIA occurs on flowing or near-stagnant ice ('open' and 'closed' types of BIA; Sinisalo and Moore, 2010). The latter occurs in the vicinity of nunataks that block the ice flow, so the ice becomes stagnant (Bintanja, 1999). If the local SMB is negative, an equilibrium between ice inflow and surface ablation will be reached. BIAs also occur on fast-flowing ice. Their development depends on the ratio of surface mass removal and ice-flow velocity. When we consider an iceflow trajectory from the ice divide to the ice shelf, the firn column that is carried by the ice grows or shrinks, depending on the local SMB (Fig. 1). The firn layer mass balance (FMB) can be viewed as the difference between the SMB and the transition rate from firn to ice at the bottom of the firn layer. Near the ice divide (left in Fig. 1), ice flow is slow and the firn layer is usually in equilibrium with the $\mathrm{SMB}$, making the $\mathrm{FMB}$ equal to zero and the firn layer thickness constant in time. When the ice column flows into a region with higher SMB, the firn layer will grow. Likewise, the firn layer will shrink if an area of smaller SMB is encountered. In ablation areas, the entire firn layer can be removed, exposing the glacier ice at the surface, and thereby creating a BIA. When the ice column subsequently flows into a region with positive $\mathrm{SMB}$, snow will start to accumulate at the surface, forming a new firn column. These types of BIAs are often found along the coastal margins of East Antarctica or on valley glaciers in mountainous areas (e.g. Byrd and Beardmore Glaciers; Brown and Scambos, 2004), where strong katabatic wind accelerations cause drifting-snow erosion and high sublimation rates (Frezzotti and others, 2005; Scarchilli and others, 2010; Lenaerts and others, 2012b).

In this study we focus on Byrd Glacier (BG; $80-81^{\circ} \mathrm{S}$, $\left.157-160^{\circ} \mathrm{E}\right)$, where the latter type of BIA is found: windinduced and on flowing ice. We combine ice-velocity SMB maps with a firn-densification model (FDM), to simulate the evolution of a firn column moving through the Byrd ablation area. The focus is mainly on determining which processes and firn-layer characteristics are important for BIA formation on fast-flowing ice, rather than to precisely quantify these effects. The different models and datasets are introduced first. Thereafter, the application to BG is discussed, including sensitivity experiments in which varying strengths of BIA feedback mechanisms are imposed.

\section{Atmospheric forcing}

Atmospheric forcing is provided by a simulation at $5.5 \mathrm{~km}$ horizontal resolution of the regional atmospheric climate model RACMO2 (Van Meijgaard and others, 2008; Lenaerts and others, 2012b). In previous runs at 27 and $55 \mathrm{~km}$ resolution, RACMO2 realistically simulated the Antarctic near-surface climate and SMB (Van de Berg and others, 2005; Lenaerts and others, 2012a). The model includes a module to calculate drifting-snow transport and sublimation, processes that significantly contribute to the SMB on both local and icesheet-wide scales (Lenaerts and Van den Broeke, 2012). Drifting-snow processes in the model lead to an increased extent of ablation $(\mathrm{SMB}<0)$ and glazed areas $(\mathrm{SMB} \cong 0)$ in interior East Antarctica, features that are shown to be realistic (Stearns, 2011; Lenaerts and Van den Broeke, 2012; Scambos and others, 2012). However, to resolve SMB gradients on smaller scales, which are mostly related to subtle variations in topography, subsequent wind field heterogeneity and snow erosion and deposition patterns, the model resolution was enhanced to $5.5 \mathrm{~km}$ resolution and run for a single year, 2009 (Lenaerts and others, 2012c). At this resolution, it is shown that these improvements are necessary to simulate the strong wind acceleration inside the Byrd glacial valley. Due to this acceleration, the cumulative amount of drifting-snow sublimation and erosion is larger than precipitation, leading to ablation in the valley. These features are not resolved at $27 \mathrm{~km}$ resolution (Lenaerts and others, 2012c).

In this study, we use daily output of RACMO2 for the year 2009 as climatic forcing for the FDM. We assume this forcing is representative of the long-term climate, a reasonable assumption since the 2009 SMB of this part of East Antarctica (Ice, Cloud and land Elevation Satellite (ICESat) basin 15 and 16; Shepherd and others, 2012) is $49 \mathrm{Gta}^{-1}$, which is comparable to the 1979-2010 average of $47 \mathrm{Gta}^{-1}$.

\section{Firn-densification model}

We use a one-dimensional, time-dependent FDM that calculates density, temperature and liquid water content in a vertical firn column (Ligtenberg and others, 2011). The FDM is forced at the surface with output from RACMO2; SMB components (precipitation, surface sublimation, surface melt and drifting-snow processes), skin temperature and $10 \mathrm{~m}$ wind speed. The climate forcing along the ice-flow trajectory is defined as the four-point inverse-distance weighted average of the nearest RACMO2 gridpoints. To keep the FDM computationally feasible, while taking into account the varying climate on locations along the flowline, a constant climate of 10 years is chosen before it is moved to the new trajectory point with its associated different climate. The trajectory extends far enough upstream of the BIA to build up and refresh a complete firn column, thereby spinning-up the FDM.

In previous studies, the FDM was used to simulate firn and surface height changes at a fixed position (Ligtenberg and others, 2012; Pritchard and others, 2012), whereas this study focuses on simulating the evolution of a firn layer that moves along an ice-flow trajectory. Also, the extreme conditions (ablation, high wind speeds) of the $\mathrm{BG}$ region are a rigorous test for the FDM compared with the accumulation zone of an ice sheet. For this purpose, some slight modifications to the FDM physics have been introduced, in comparison with the version of Ligtenberg and others (2011).

Firstly, drifting-snow erosion/deposition is added as a mass removal/addition term, as it is one of the driving forces of BIA 

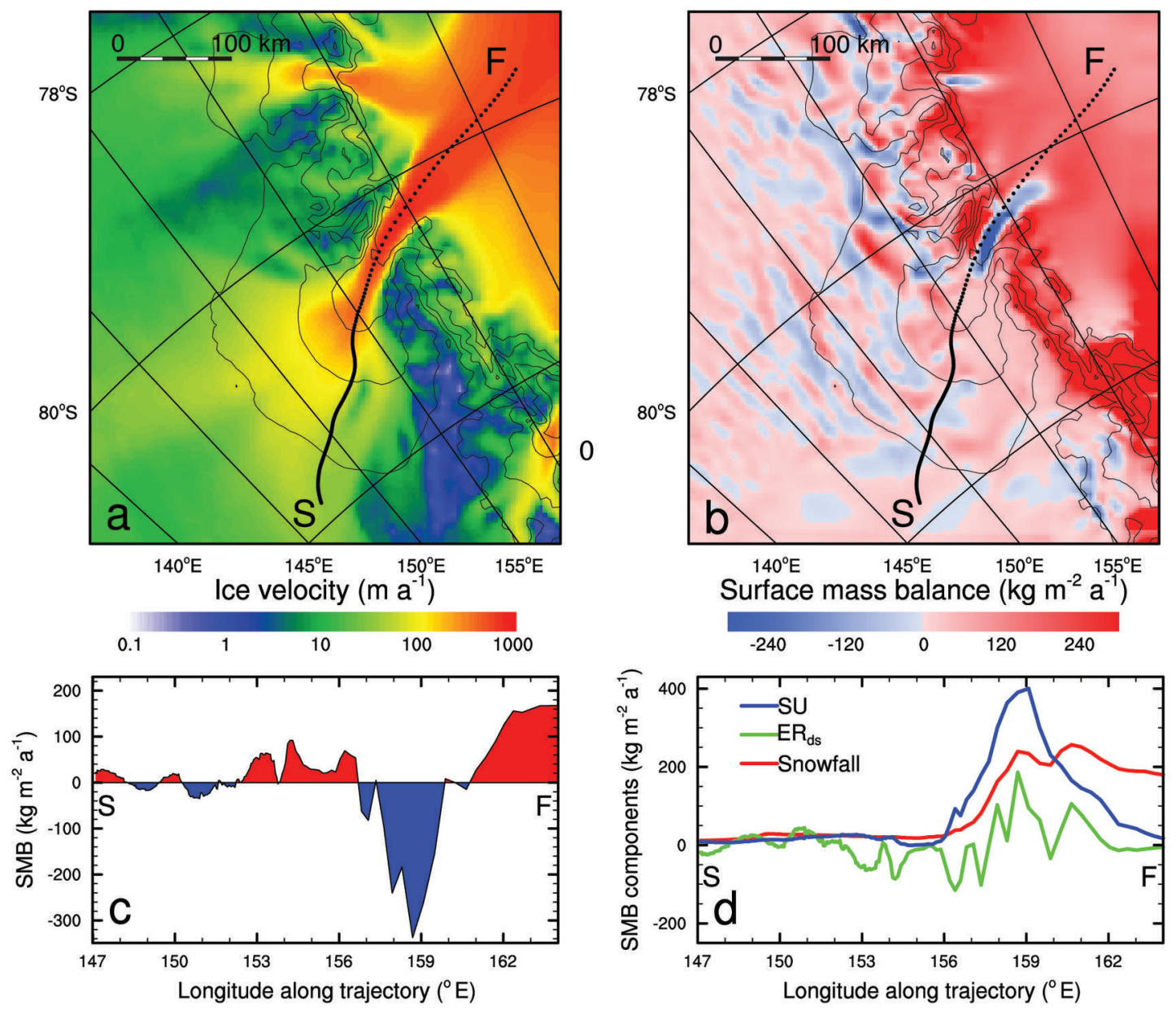

Fig. 2. Ice-flow trajectory starting at ' $S$ ' on the East Antarctic plateau and ending at ' $F$ ' on the Ross Ice Shelf. Colors indicate ice-flow velocity in (a), and modelled SMB in (b). Dots indicate a trajectory point every 10 years and the solid curves indicate topographic height contours with $500 \mathrm{~m}$ spacing. (c) The SMB and (d) its components, snowfall, combined surface and drifting-snow sublimation (SU) and erosion/ deposition by drifting snow (ER $\left.\mathrm{ds}_{\mathrm{s}}\right)$, along the trajectory.

formation (Takahashi and others, 1988). Every model time-step, RACMO2-simulated SMB components (snowfall, rainfall, snowmelt, surface sublimation, drifting-snow sublimation and drifting-snow erosion/deposition) are added to or removed from the top model layer with either the density of fresh snow (mass addition) or the density of the top model layer (mass removal). Secondly, the FDM must be able to accommodate a complete removal of the model firn layer. This is done by adding new layers with the density of ice at the bottom of the model firn layer when a minimum number of model layers is reached (50). Thirdly, the semi-empirical expression for the densification of firn used in the FDM depends on average accumulation $(\dot{b})$, and temperature (Herron and Langway, 1980; Arthern and others, 2010; Ligtenberg and others, 2011), and is therefore physically unusable in ablation areas. Therefore, we assume that $\dot{b}$ is always at least equal to $15 \mathrm{~kg} \mathrm{~m}^{-2} \mathrm{a}^{-1}$, i.e. firn densification is a continuous process. Even in a negative accumulation area, snowfall events occur that add mass and therefore increase pressure on the firn layers, thereby enhancing firn densification. When mass is removed from the surface, pressure on the firn layers is lowered, but this does not cause 'negative' firn densification, i.e. no air is added to the firn layer. The value of $\dot{b}=15 \mathrm{~kg} \mathrm{~m}^{-2} \mathrm{a}^{-1}$ was chosen based on model experiments, and gives comparable densification rates at depth between ablation and accumulation regions. Firn models that use the overburden pressure as a measure for firn densification (e.g. Barnola and others, 1991; Spencer and others, 2001) are not affected by this, as they do not use the average accumulation rate in their equations. Like most firn models, our FDM is calibrated to density data from accumulation zones. In the absence of similar data from ablation areas, we currently have to rely on these models without being able to directly validate the modeled density profiles.

\section{Ice velocity}

To obtain a trajectory along an ice flowline, the AIS ice velocity field of Rignot and others (2011) is bilinearly interpolated onto the grid of RACMO2 $(5.5 \mathrm{~km})$. Firstly, a location downstream of the ablation area (i.e. negative SMB in RACMO2) is selected and the trajectory is calculated in a stepwise fashion in the upstream direction, using the average flow velocity and direction of the four neighboring points. A time-step of 10 years is used. These steps are repeated until the trajectory reaches the East Antarctic plateau, where the climate is relatively stable and ice velocities are relatively low, conditions that are required to spin-up the model firn layer. Figure 2 shows the resulting ice-flow trajectory and SMB map and profile along the trajectory crossing BG. The trajectory starts at point ' $\mathrm{S}$ ' on the East Antarctic plateau, at $>2000$ ma.s.l., where ice velocity is relatively low 

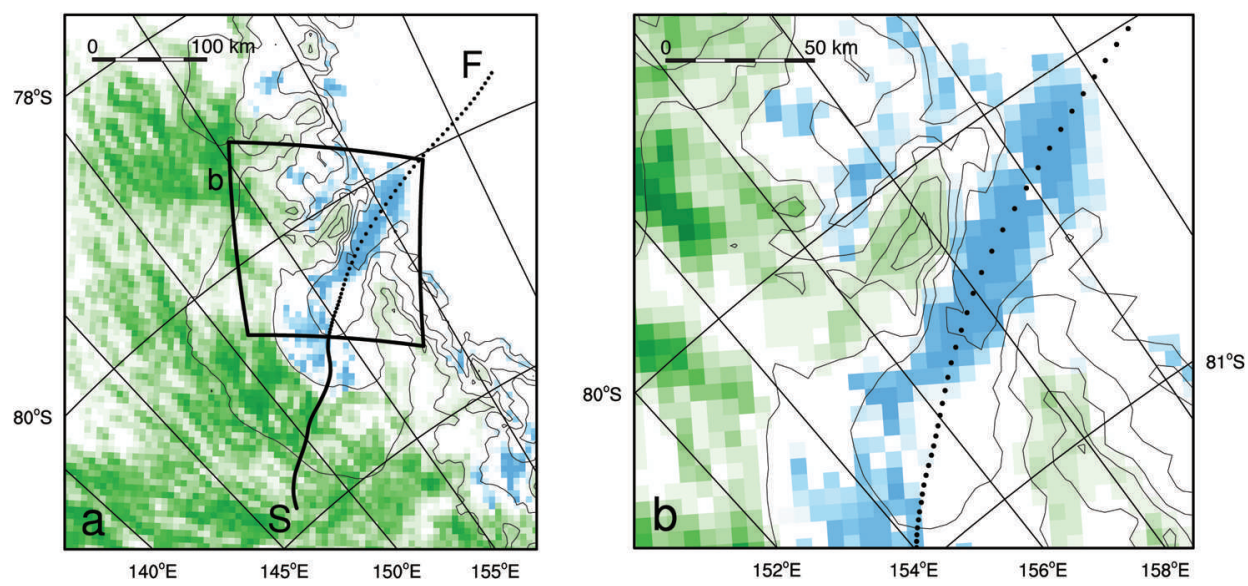

Fig. 3. (a) Ice-flow trajectory starting at ' $S$ ' on the East Antarctic plateau and ending at ' $F$ ' on the Ross Ice Shelf. Shaded background colors are observed 'wind-glaze' surface (green; from Das and others, 2013) and blue-ice areas (blue; after Scambos and others, 2012). (b) Enlargement of the Byrd Glacier region in (a).

$\left(\sim 50 \mathrm{~m} \mathrm{a}^{-1}\right)$, and ends at point ' $\mathrm{F}^{\prime}$ on the Ross Ice Shelf (RIS). The ice velocity in the first half of the trajectory is low; the more widely spaced trajectory dots indicate the increasing speed when the trajectory enters the narrow valley of BG, where the highest ice-flow velocities are reached (up to $1200 \mathrm{~m} \mathrm{a}^{-1}$; Fig. 2a). Ice-flow speed remains high when the trajectory leaves the narrow valley and enters the RIS.

At the start of the trajectory, the SMB is close to zero (Fig. 2b and c), with small SMB components (Fig. 2d). Alternating patterns of ablation and accumulation are caused by subtle differences in the RACMO2 topography that initiate acceleration and deceleration of the wind speed (Lenaerts and others, 2012c). In turn, this determines patterns of erosion or deposition of drifting snow (Fig. 2d). This area of (near-)ablation agrees well with the 'wind-glaze' area found by Das and others (2013), shaded green in Figure 3. The Transantarctic Mountain range represents a large gradient in elevation and precipitation, leading to higher SMB values on the RIS to the east $\left(\sim 150 \mathrm{~kg} \mathrm{~m}^{-2} \mathrm{a}^{-1}\right)$ compared with the icesheet plateau to the west ( -20 to $20 \mathrm{~kg} \mathrm{~m}^{-2} \mathrm{a}^{-1}$ ). In the valleys of $\mathrm{BG}$ and Darwin Glacier $\left(79^{\circ} \mathrm{S}, 159^{\circ} \mathrm{E}\right)$ the $\mathrm{SMB}$ is dominated by large drifting-snow sublimation and erosion rates due to strong katabatic winds, leading to a locally negative SMB. Downstream at the RIS, the SMB turns positive due to more precipitation and lower wind speeds.

\section{Blue-ice area}

Scambos and others (2007) present a satellite image algorithm for mapping snow grain size, and use it to estimate BIA extent. Using two bands from the Moderate Resolution Imaging Spectroradiometer (MODIS) satellite sensor, specifically its two $250 \mathrm{~m}$ resolution bands (band 1: red visible light at $620-670 \mathrm{~nm}$; band 2: near-infrared at $841-876 \mathrm{~nm})$, grain size is determined by the increased absorption of infrared light as grain size increases. The MODIS band 1 and 2 data are corrected for sensor drift, satellite and solar geometry, and atmospheric absorption, and are converted to top-of-the-atmosphere reflectivity before using a look-up table of snow grain size and reflectivity in each band derived from a model (Ricchiazzi and others, 1998; Painter and others, 2003). A map of snow grain size produced from a MODIS mosaic of the Antarctic continent was produced and described by Scambos and others (2007), and data for this 2003-04 mosaic and a second mosaic produced from 2008-09 data (Scambos and others, 2012) are available from NSIDC (nsidc.org).

An earlier Landsat-based study by Brown and Scambos (2004) used a supervised classification approach to map wind-induced BIAs near BG for seasonal and interannual variations in extent. Comparing the grain-size mapping results of the MODIS bands 1 and 2 approach with this earlier study indicates that an effective threshold for mapping BIA boundaries from optically determined snow grainsize data is $400 \mu \mathrm{m}$. Figure 3 shows the resulting BIA extent (in blue) when this threshold and the method described above are used. The two Mosaic of Antarctica grain-size datasets give results consistent with the BIAs considered by Brown and Scambos (2004), and other mapped Antarctic BIAs (e.g. Van den Broeke and others, 2006). They indicate that the BIA in the central BG trunk extends from just east of $155^{\circ} \mathrm{E}$ to just west of $162^{\circ} \mathrm{E}$. However, these boundaries can vary due to seasonal and interannual variations in snow cover. For example, the eastern extent boundary varies between $161.6^{\circ} \mathrm{E}$ and $161.9^{\circ} \mathrm{E}$ in the 2004 and 2009 mappings. The western boundary, and most other windinduced BIAs in the region, are near identical in both mappings. The BG BIA is approximately $125-130 \mathrm{~km}$ alongflow and $20-30 \mathrm{~km}$ wide through the glacier trunk, extending quite close to the valley walls of the glacier. Along the ice-flow trajectory calculated in the previous subsection (Fig. 2C), the BG BIA extends from $156.4^{\circ} \mathrm{E}$ to $161.8^{\circ} \mathrm{E}$ (Fig. 3b). The trajectory also passes through a smaller BIA, upstream of $\mathrm{BG}$, which extends from $150.8^{\circ} \mathrm{E}$ to $152.1^{\circ} \mathrm{E}$.

\section{RESULTS}

Figure $4 \mathrm{a}$ shows the modelled evolution of the firn mass along the ice-flow trajectory through BG with the control climate forcing (Fig. 2). Firn mass is defined as the vertically integrated mass of model layers with a density less than $830 \mathrm{~kg} \mathrm{~m}^{-3}$, generally assumed to be the pore close-off depth and the boundary between firn and glacier ice (Herron and Langway, 1980; Ligtenberg and others, 2011). The upper $x$-axis indicates the elapsed time during the simulation, starting from the present day and assuming a 
steady-state climate throughout the period. Firn mass evolution follows that of the local SMB (Fig. 2c): firn mass decreases/increases with a negative/positive SMB. To create a realistic firn layer at the start of the trajectory, the climate of the first trajectory point is used to spin-up the FDM until the firn mass reaches a steady state ( $\sim 40$ tons), indicating that the firn layer is in equilibrium with the local climate. For the next 2500 years, the trajectory moves slowly eastwards and SMB is small, but positive (Fig. 2c), causing the firn mass to remain relatively constant. When the trajectory enters a negative $\mathrm{SMB}$ region $\left(148-152^{\circ} \mathrm{E}\right)$, the firn mass steadily drops and becomes zero around $152^{\circ} \mathrm{E}$. Due to the low ice velocities on the East Antarctic plateau, the firn layer spends $\sim 80 \%$ of the total time in the $147-152^{\circ} \mathrm{E}$ sector. Because the firn column resides a long time in this near-zero SMB environment, the entire firn layer is removed. These conditions indicate that the $147-152^{\circ} \mathrm{E}$ region is prone to BIA formation, as supported by Figure 3a. This BIA will be referred to as 'Upper BIA'. The strong nonlinear character of the trajectory timeline is indicated by the time axis in Figure $4 a$.

Figure $4 \mathrm{~b}$ shows the components of the firn depth change rate due to the different firn and SMB processes (Ligtenberg and others, 2011, 2012). Around $153^{\circ} \mathrm{E}$ the ice velocity increases as it approaches the BG valley, and moves into a positive $\mathrm{SMB}$ region. Accumulation is mainly due to increased drifting-snow deposition (Fig. 4b), and results in the build-up of a new firn layer and increasing firn mass (Fig. 4a). The $S M B$ remains positive until $157^{\circ} \mathrm{E}$, because of low sublimation and periodically high drifting-snow deposition, further enhancing the firn mass. When the trajectory enters the BG valley, firn mass decreases rapidly, but not all the mass of the firn layer is removed (Fig. 4a). The negative SMB is mainly caused by drifting-snow sublimation and erosion, but is counteracted by an increase in snowfall (Fig. 4b). With ice velocities $>1 \mathrm{~km} \mathrm{a}^{-1}$, it takes only $\sim 70$ years for the ice to move through the BG ablation area $\left(157-160^{\circ} \mathrm{E}\right)$, during which time roughly half the existing firn mass is removed. When the trajectory enters the RIS $\left(\sim 162^{\circ} \mathrm{E}\right)$ the ice velocity remains high, and the annual SMB becomes significantly positive $\left(>150 \mathrm{~kg} \mathrm{~m}^{-2}\right)$, due to increasing snowfall and reduced snowdrift activity. As a consequence, firn mass increases rapidly to form a thicker firn layer, which is characteristic for most of the Antarctic ice sheet and ice shelves (Ligtenberg and others, 2011).

The FDM does not simulate a BIA on BG, with a significant amount of firn mass still present at its minimum $\left(10450 \mathrm{~kg}\right.$ at $\left.160.6^{\circ} \mathrm{E}\right)$. With an average annual SMB of $-200 \mathrm{~kg} \mathrm{~m}^{-2}$, it would take another $\sim 70$ years to remove the remainder of this firn layer. This can either mean that the ice velocity is overestimated, transporting the firn layer too quickly through the ablation region, or that $\mathrm{SMB}$ is not accurately simulated. The second option is more likely, since the ice velocity should be halved in order to create the BG BIA, while the uncertainty in local ice velocity is only $\sim 5 \mathrm{ma}^{-1}$ (Rignot and others, 2011). SMB on BG is less certain, as RACMO2 simulations for the Antarctic ice sheet (Van de Berg and others, 2006; Lenaerts and others, 2012a; Ligtenberg and others, 2013) are initialized with a homogeneous firn pack covering the entire ice sheet, which is a valid assumption for $\sim 98 \%$ of the Antarctic ice sheet. However, at locations that experience significant snowmelt (e.g. the George VI Ice Shelf) or have a negative SMB (e.g. BIAs), this assumption is not longer valid. Although

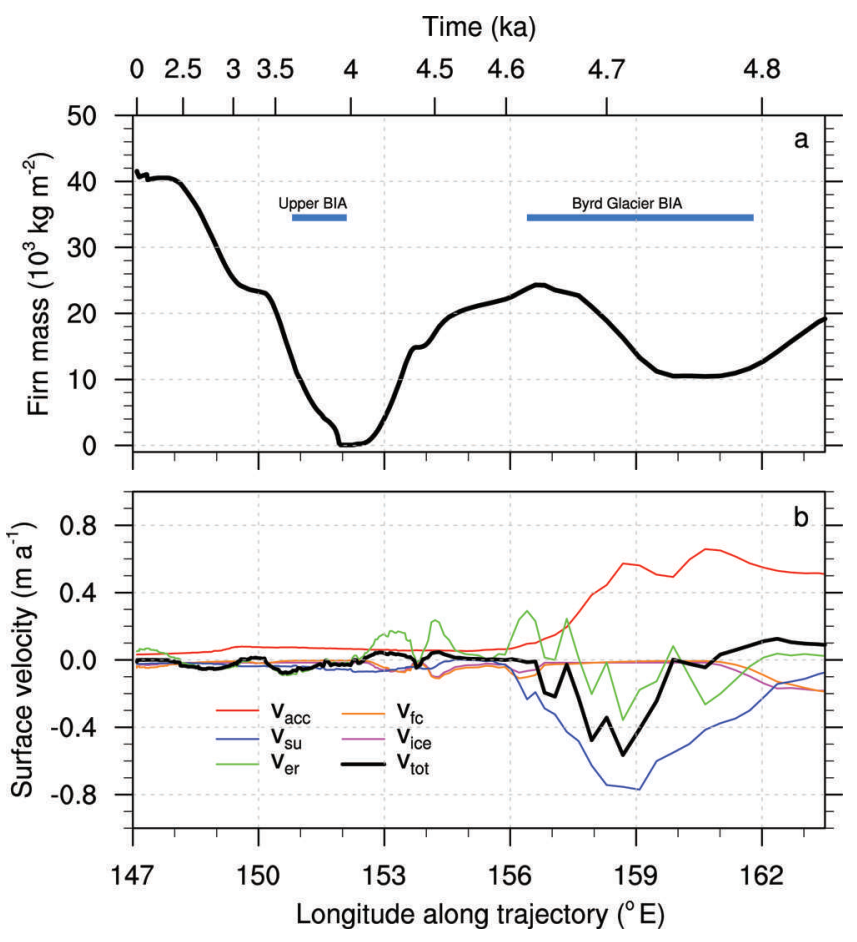

Fig. 4. (a) Evolution of firn mass and (b) corresponding vertical surface velocities for the control simulation, along the trajectory shown in Figure 2b. Vertical surface velocity components due to snowfall $\left(v_{\text {acc }}\right)$, sublimation $\left(v_{\mathrm{su}}\right)$, drifting-snow erosion/deposition $\left(v_{\mathrm{er}}\right)$, firn compaction $\left(v_{\mathrm{fc}}\right)$, firn-ice formation $\left(v_{\text {ice }}\right)$ and the total vertical surface velocity $\left(v_{\text {tot }}\right)$ are shown. The red, blue and green surface velocities correspond to the red, blue and green SMB components in Figure $2 \mathrm{~d}$. Both the longitude and elapsed time are shown. Blue bars in (a) indicate the locations of the 'Upper BIA' and the 'Byrd Glacier BIA'.

RACMO2 has an interactive firn layer, and the $5.5 \mathrm{~km}$ RACMO2 simulation considered here is initialized with the $27 \mathrm{~km}$ RACMO2 simulation of Lenaerts and others (2012a), the $\sim 30$ years of spin-up are not long enough to remove the entire model firn layer and form a BIA in RACMO2. Therefore, the feedback processes that play a major role in the formation and persistence of a BIA are not (fully) represented in RACMO2. In the next subsection, these feedback processes and their influence on the evolution of the firn layer around BG are discussed.

\section{BIA feedback mechanisms}

Positive feedback processes active at the BIA surface are related to (1) the darker surface of a BIA compared to snow and (2) the smoother and harder surface of a BIA. The albedo of freshly fallen snow can be as high as 0.85, while the albedo of blue ice is in the range 0.5-0.6 (Bintanja and Van den Broeke, 1995), so blue ice absorbs three to four times more solar radiation than fresh snow. A part of this extra energy is transformed into heat, making the surface of BIAs warmer than the surrounding snow-covered areas. Bintanja and Van den Broeke (1995) found that, averaged over one summer, the surface temperature of a BIA was $6.4 \mathrm{~K}$ higher than over the surrounding snow-covered area. In the FDM, this effect was mimicked by adding a sine-like surface temperature correction, maximized at the summer solstice $(+6 \mathrm{~K})$ and zero when the sun is below the horizon at $80^{\circ} \mathrm{S}$ (Fig. 5a). The associated increase in sublimation rate follows 

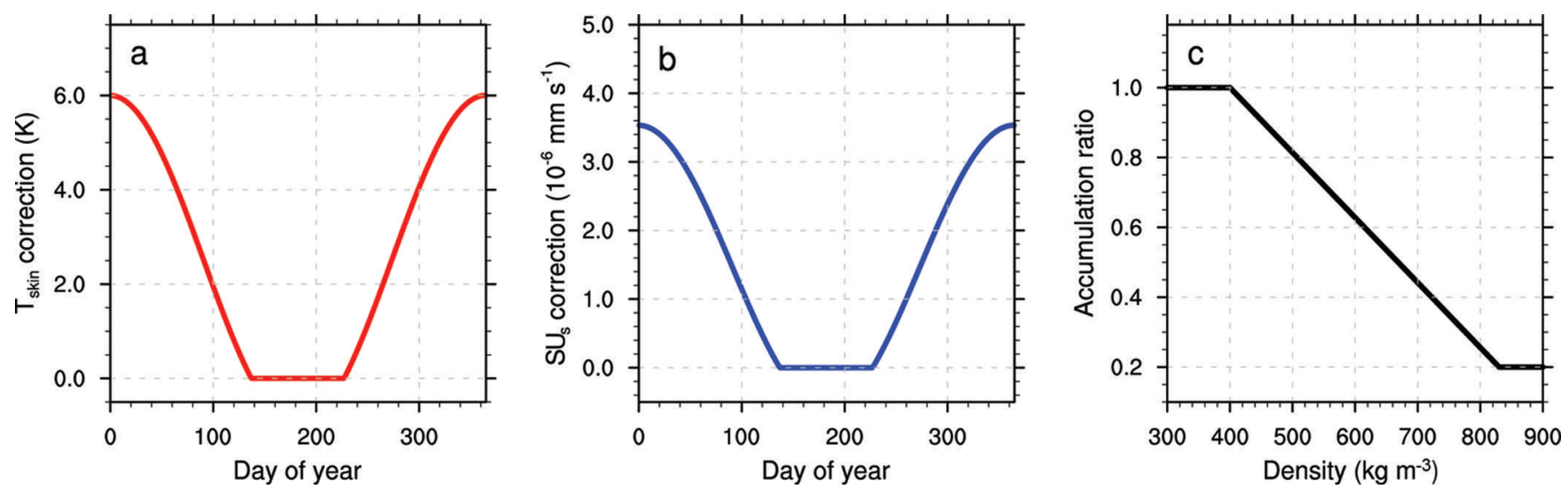

Fig. 5. Imposed idealized positive feedback mechanisms on a BIA, for (a) surface temperature, $T_{\text {skin, }}$ (b) surface sublimation, $\mathrm{SU}_{\mathrm{s}}$, and (c) accumulation ratio (snowfall and deposition of drifting snow).

the correction for temperature, since the effects are coupled. At the summer solstice the sublimation correction is maximized at $+0.3 \mathrm{~mm} \mathrm{~d}^{-1}$ (Fig. 5b). This value is based on the difference in average summer latent heat flux above a BIA and snow (10 $\mathrm{W} \mathrm{m}^{-2}$; Bintanja and Van den Broeke, 1995). The magnitude of both corrections (temperature and sublimation) is made a function of the density of the upper model

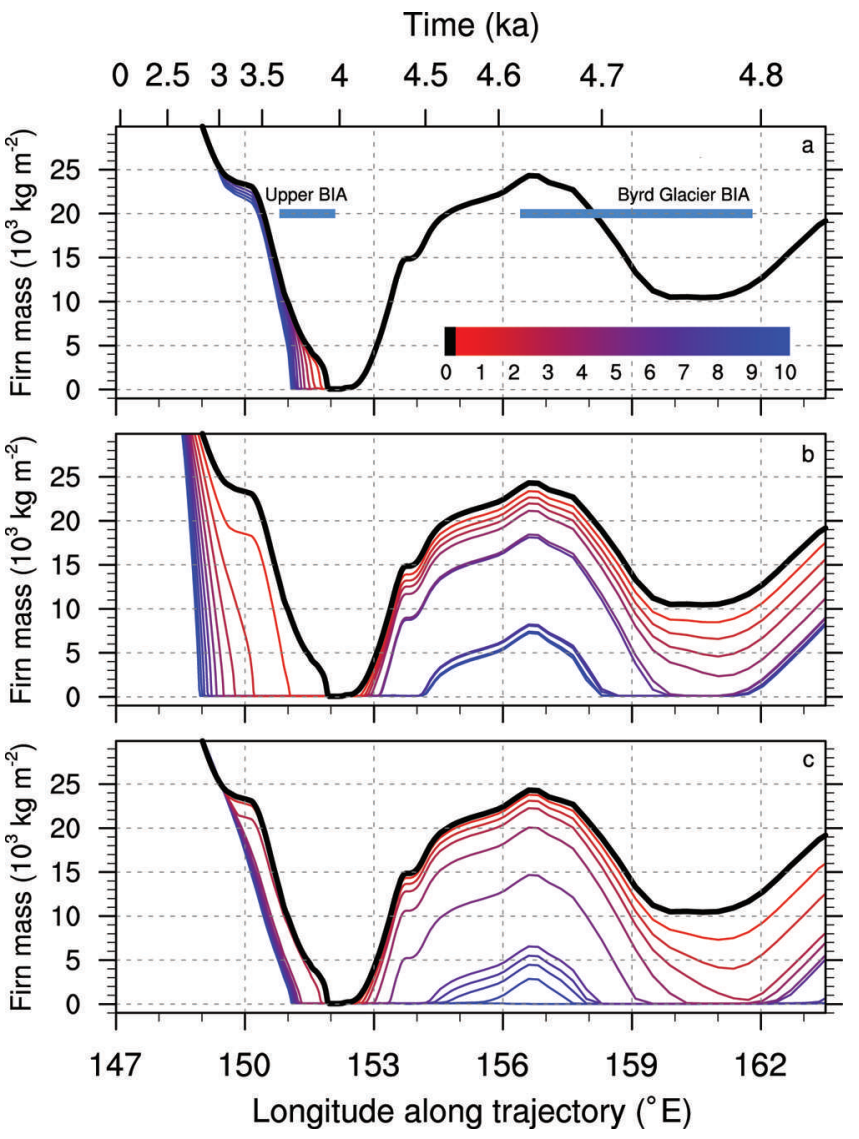

Fig. 6. Evolution of firn mass along the trajectory for (a) temperature, (b) sublimation and (c) accumulation experiments, along the trajectory shown in Figure $2 \mathrm{~b}$. The control simulation (thick black curve, same as Fig. 4a), and light (red, 1) to strong (blue, 10) feedback experiments are shown. Both the longitude and elapsed time are shown. Blue bars in (a) indicate the locations of the 'Upper $\mathrm{BIA}^{\prime}$ and the 'Byrd Glacier BIA'. layer: no correction is applied for a snow surface $(\rho<400$ $\mathrm{kg} \mathrm{m}^{-3}$ ) and the full correction is applied for blue ice $\left(\rho>830 \mathrm{~kg} \mathrm{~m}^{-3}\right)$, with a linear dependency in between. The latter threshold is chosen as it represents the approximate pore close-off density, at which air bubbles get trapped in the ice, and firn characteristics no longer change appreciably.

The smoother and harder surface of a BIA makes it more difficult for precipitating snow particles to form a continuous snow layer at the surface (Van den Broeke and Bintanja, 1995a), especially during strong wind events. Therefore, less snow will accumulate at the surface of a BIA. To compensate for this effect, a fraction of the simulated snowfall and drifting-snow deposition is assumed to be removed from the surface, depending on the density of the surface. The threshold values for the surface density (400 and $830 \mathrm{~kg} \mathrm{~m}^{-3}$ ) are similar to that for the temperature and sublimation feedback. For a snow surface, all accumulation remains at the surface (fraction $=1.0$ ), whereas on a BIA the fraction decreases to 0.2 , meaning that only $20 \%$ of the accumulation is allowed to accumulate on the surface (Fig. 5c).

To investigate the sensitivity of BIA formation to the above schematic adjustments, an ensemble of FDM simulations was performed with varying strengths. The feedback mechanisms as described in the previous paragraphs, were used as the maximized values (1.0, or $100 \%$ ): a $6 \mathrm{~K}$ temperature increase, a latent heat flux increase of $10 \mathrm{~W} \mathrm{~m}^{-2}$ (e.g. a sublimation increase of $0.3 \mathrm{~mm} \mathrm{~d}^{-1}$ ) and an accumulation fraction of $20 \%$. In each consecutive run, numbered X10 to $\mathrm{X} 1$, the feedback strength was decreased by fractional increments of 0.1 . For example, the 'T6-S4-A3' acronym refers to a simulation with a temperature increase of $3.6 \mathrm{~K}$ $(0.6 \times 6 \mathrm{~K})$, a latent heat flux (or sublimation) correction of $0.12 \mathrm{~mm} \mathrm{~d}^{-1}\left(0.4 \times 0.3 \mathrm{~mm} \mathrm{~d}^{-1}\right)$ and an accumulation fraction of $0.76(1.0-(0.3 \times 0.8))$. The firn layer simulation without the feedback mechanisms ('control'), as shown in Figure $4 \mathrm{a}$, is thus ' $\mathrm{TO}-\mathrm{SO}-\mathrm{AO}^{\prime}$.

\section{Sensitivity experiments}

Figure 6 shows the evolution of firn mass along the ice-flow trajectory with the three feedback mechanisms activated separately with varying strengths: (a) temperature, (b) sublimation and (c) accumulation. The temperature feedback appears to have a minor effect on the simulated firn mass; only in the low-velocity region of the trajectory $\left(151-152^{\circ} \mathrm{E}\right)$ does the increase in surface temperature result 
in a significant change from the control run. The higher temperatures lead to higher firn densification rates, causing a faster firn/ice transition than in the control run and therefore earlier BIA formation. On BG no change in firn mass evolution is simulated for increased temperatures; BIA feedback processes are only activated when the upper layer density becomes $>400 \mathrm{~kg} \mathrm{~m}^{-3}$, and this threshold is not reached on BG. Apparently, snowfall and drifting-snow deposition are large and constant enough for the upper snow layer density to remain low.

In the sublimation (Fig. 6b) and accumulation (Fig. 6c) experiments, the impact on firn mass is much larger. Both have similar effects on the firn layer: an increase in sublimation or a decrease in snow accumulation both decrease the SMB at the surface. For moderate feedback strengths (1-4), firn mass is reduced fairly linearly over the fast-ice-flow region $\left(153-162^{\circ} \mathrm{E}\right)$. This is mainly caused by a lag effect that originates in the Upper BIA, where glacier ice is at the surface and the influence of the feedback processes therefore large. In both simulations, it takes more time for the new firn layer to re-establish itself and thereby deactivate the feedback mechanisms. When this happens $\left(\sim 153^{\circ} \mathrm{E}\right)$, the $\mathrm{SMB}$ forcing is again equal to the control run and the evolution of firn mass is similar until $159^{\circ} \mathrm{E}$. Here BIA feedback processes again start to play a role as the upper layer density increases, causing the firn mass to reduce more rapidly. For relatively high feedback strengths (S5 and A4 and higher), a BIA at BG is simulated (firn mass $=0$ at $160^{\circ} \mathrm{E}$ ). These results suggest that the feedback mechanisms described here are essential to sustain the BG BIA. If no BIA were present, the feedback mechanisms would not be active and the climate would be comparable to the RACMO2 output, which does not lead to a BIA on BG (Fig. 4).

Between simulations S6 and S7 (and also between A5 and A6), a rapid change in firn mass prior to $B G\left(154-158^{\circ} \mathrm{E}\right)$ occurs, which is also initiated by the previously discussed lag effect. The SMB around $153^{\circ} \mathrm{E}$ (Fig. 2c) is, in combination with the imposed increase in sublimation (or decrease in accumulation), too small to initiate fast firn layer growth. As the density of the upper layers remains high, the feedback processes remain active and no new firn layer is established. Only at $\sim 154^{\circ} \mathrm{E}$ is the peak in SMB due to drifting-snow deposition large enough to start the formation of a significant firn layer. Hereafter, the feedback mechanisms are switched off and firn mass increases regularly until $157^{\circ} \mathrm{E}$. Only for the strongest feedback simulation (A10, accumulation reduced by $80 \%$ ) is no firn layer simulated over the entire $152-164^{\circ} \mathrm{E}$ section of the trajectory.

Although the sublimation and accumulation sensitivity simulations give quite similar results, there are also some notable differences. In the sublimation simulations, the onset of the Upper BIA occurs earlier with every experiment, whereas for the accumulation simulations an optimum is already reached in simulation $A 3$. In this near-zero $S M B$ environment, the individual SMB components are small (Fig. 2d) and because the accumulation feedback mechanism is prescribed as a fraction of the absolute amount, the imposed accumulation effect is also rather small. The sublimation effect, however, is prescribed as an absolute value and therefore has a continuously increasing effect. In the faster-flowing sections of the trajectory $\left(154-157^{\circ} \mathrm{E}\right)$, the reverse effect is visible; here the sublimation simulations converge, with the strongest feedback simulations (S7-S10) showing the same firn mass. When individual SMB

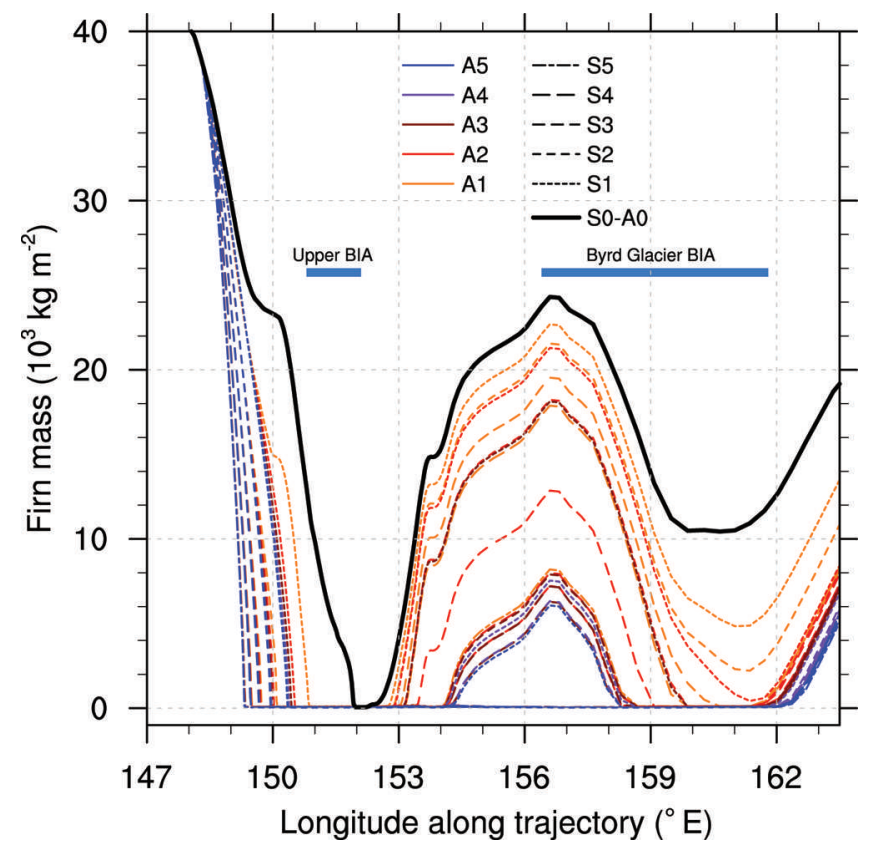

Fig. 7. Evolution of firn mass along the trajectory shown in Figure $2 \mathrm{~b}$ for simulations with a combination of accumulation (line color) and sublimation (line style) feedback processes. The control simulation is included (thick black curve, same as Fig. 4a) and numbers indicate the strength of the feedback process, varying from light (1) to moderate (5). Blue bars indicate the locations of the 'Upper BIA' and the 'Byrd Glacier BIA'.

components are large, the absolute effect of the sublimation feedback is small and here the relative accumulation feedback has a much bigger impact. This is reflected in the reduction of firn mass in each subsequent simulation (A1-A10). When the trajectory enters the RIS $\left(>162^{\circ} \mathrm{E}\right)$, all sublimation experiments form a firn layer, whereas the firn mass in the high-impact accumulation experiments $(>A 8)$ remains zero.

\section{Combination of feedbacks}

A combination of the feedback mechanisms is more realistic; to that end 121 experiments with different combinations of the sublimation and accumulation effects were performed. The temperature effect, although of minor importance, is also included and is prescribed to have the same relative strength as the sublimation effect. Figure 7 shows the results of 25 moderate combination simulations (A1-A5, combined with S1-S5). Similar patterns to those in Figure $6 b$ and c emerge; (1) a faster formation of the Upper BIA, (2) the firn layer growth at the 153 or $154^{\circ} \mathrm{E}$ accumulation event and (3) the varying presence and extent of the BG BIA.

The formation of the Upper BIA is similar to Figure $6 \mathrm{~b}$, as sublimation is the main driver of the formation of this BIA. With each increase in sublimation feedback strength, the Upper BIA is formed earlier, while an increase in accumulation effect induces significantly less change. The difference in maximum firn mass prior to BG (at $156^{\circ} \mathrm{E}$ ) also shows the same pattern as for the separate sublimation and accumulation simulations (Fig. $6 \mathrm{~b}$ and c). For the control run it peaks at $\sim 24$ tons, and for moderate feedback simulations ( S2-A2) this reduces to 18-22 tons, due to the slight time lag in firn layer growth around $153^{\circ} \mathrm{E}$. From simulation S3-A3 onwards, 

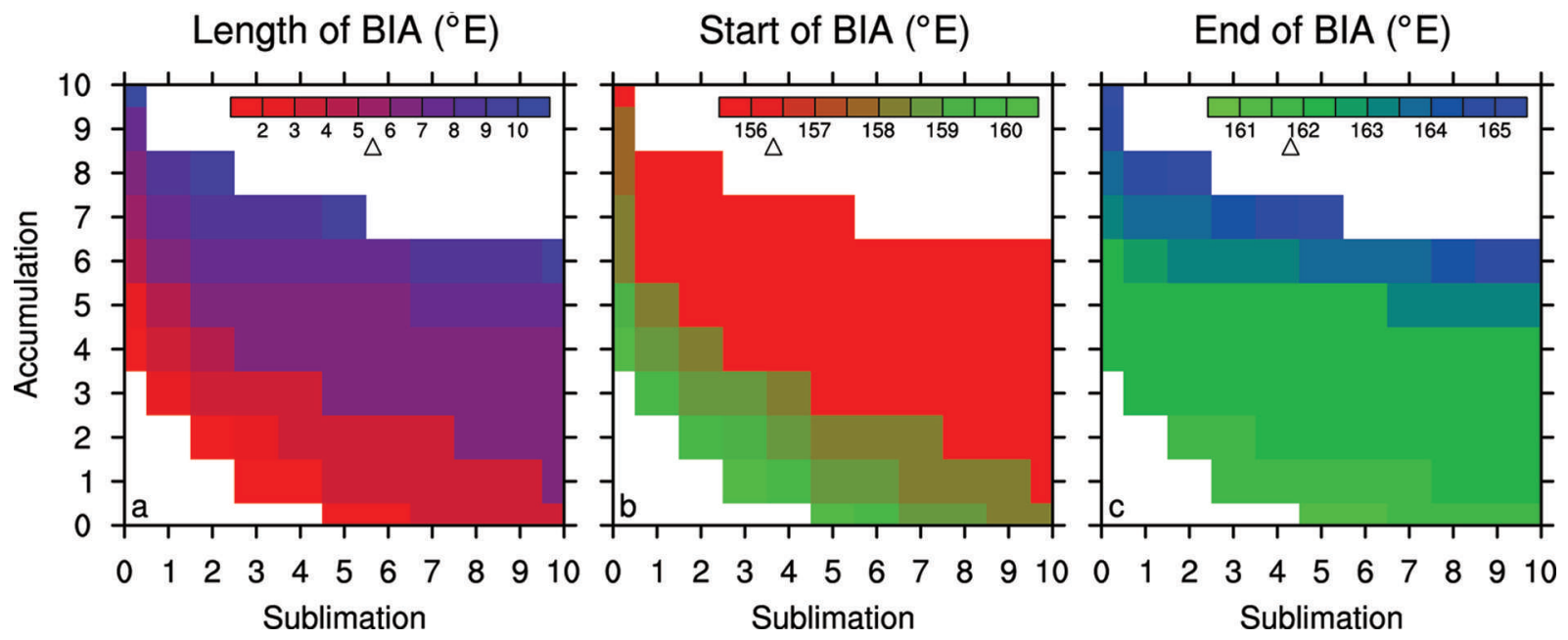

Fig. 8. (a) Length, (b) start position and (c) end position of the simulated BG BIA, for simulations with a combination of accumulation and sublimation feedback processes. Axis labels indicate the strength of the feedback process, varying from light (1) to strong (10). The observed BIA characteristics are indicated by the triangles.

the positive $\mathrm{SMB}$ event of $153^{\circ} \mathrm{E}$ is not sufficient and the build-up of a firn layer is delayed until the positive SMB event at $154^{\circ} \mathrm{E}$, thereby generating significantly less firn mass ( $\sim 7$ tons). For stronger feedbacks, no firn layer is simulated and the BIA extends from 150 to $162^{\circ} \mathrm{E}$. The presence and/or length of the BG BIA depends mostly on this maximum firn layer mass prior to BG. If this firn mass is larger, more mass needs to be removed and the BIA forms later or not at all. The firn layer growth at the end of BG BIA is more robust, and is predicted to be $\sim 162^{\circ} \mathrm{E}$ in all experiments.

Figure 8 summarizes (a) the length, (b) the start position and (c) the end position of the BG BIA for the different model experiments, expressed in degrees longitude. The white area in the lower-left corner represents simulations in which no BIA develops. The white area in the upper-right corner represents simulations in which the BIA extends from at least $152^{\circ} \mathrm{E}$ to the end of the trajectory. The latter means that the feedback processes are so strong that no new firn layer forms between the Upper and BG BIAs. For increasing strength of the feedback processes, the length of the BIA increases, with the start and end of the BIA propagating westwards and eastwards, respectively. However, the transition is not gradual; the start of the BIA shows a distinct transition between simulations that do not simulate a firn layer prior to $\mathrm{BG}$ and simulations that do (start of $\mathrm{BIA}>158^{\circ} \mathrm{E}$ and $<158^{\circ} \mathrm{E}$, respectively). Less distinct is the difference in start position above $158^{\circ} \mathrm{E}$, which indicates simulated firn layer growth from either the $153^{\circ} \mathrm{E}$ or the $154^{\circ} \mathrm{E}$ accumulation event. The end position of the BIA is more evenly distributed, with the majority of the solutions predicting the BIA terminating around $162^{\circ} \mathrm{E}$. The length of the BIA is simply the difference between the start and end position, and varies between 2 and $10^{\circ} \mathrm{E}$.

An optimal combination of accumulation and sublimation feedback strengths is hard to provide, because no combination exists that best captures the start, end and length of the BG BIA. Figures 7 and 8 show that the end location of the BG BIA is positioned rather uniformly around $162^{\circ} \mathrm{E}$, in agreement with observations. Based solely on the start position, the solutions along the line A5-S1 to A1-S9 (Fig. 8b) contain the optimal combinations. Although the start of the observed BG BIA at $156.4^{\circ} \mathrm{E}$ is not well captured, they simulate a start location of $158-158.5^{\circ} \mathrm{E}$. Experiments A4-S2, A3-S4 and A2-S5 seem the most realistic, assuming that the feedback mechanisms (accumulation and sublimation) are similar in strength.

\section{DISCUSSION}

Validation of the firn mass evolution along the trajectory remains challenging, as few detailed firn profiles are available. According to MODIS imagery, the onset of the observed BIA on BG $\left(156.4^{\circ} \mathrm{E}\right)$ is situated close to the start of the negative $\mathrm{SMB}$ region (from $156.6^{\circ}$ E onwards; Fig. 2a). In combination with the relatively high ice velocities in this region, this suggests that the upstream firn layer mass should at least be small. This is an indication that the moderate sensitivity simulations with a lower firn mass around $155-157^{\circ} \mathrm{E}$ could be more realistic than the control simulation. Moreover, most of the region of the East Antarctic plateau upstream of BG is observed to be 'windglaze' area, indicating that the firn mass is potentially low throughout the region.

The simulated firn mass is almost entirely determined by the SMB from RACMO2, which, in turn, is dominated by the variation in deposition and erosion of drifting snow in this region (Fig. $2 \mathrm{~d}$ ). The simulation of this process is complex and depends on subtle differences in topography, which are probably not fully captured at this horizontal resolution $(5.5 \mathrm{~km})$. Lenaerts and others (2012c) show large changes in the transition from 27 to $5.5 \mathrm{~km}$ horizontal resolution. It is highly likely that a further increase in resolution would enhance the drifting-snow details and further benefit the simulation of firn mass in the low-ice-velocity areas.

Location and extent of both the Upper BIA and the BG $\mathrm{BIA}$ are qualitatively correctly simulated by the FDM. For the Upper BIA, ice velocities are low to such a degree that even a slightly negative SMB can cause the complete removal of the firn layer. The simulated location of the BIA is mainly determined by the local drifting-snow erosion maximum, and is therefore sensitive to the resolved model topography, as described above. For the BG BIA to form, large ice velocities require significant negative $S M B$ conditions, potentially in combination with a small firn mass upstream 
of the high-velocity region. Otherwise the complete firn layer could not be removed in the relatively short time it spends in the ablation zone.

\section{SUMMARY}

In conclusion, the formation of a BIA is an interplay between (1) ice velocity, (2) SMB and (3) the firn mass of the existing firn layer prior to the ablation area. If the ice velocity is low enough, the SMB negative enough or the firn mass prior to the ablation area small enough, a BIA is likely to form. Otherwise, these three variables need to occur in a favorable combination in order to remove the entire firn layer and form a BIA.

The FDM of Ligtenberg and others (2011) has been adapted to simulate the formation and removal of a firn layer along an ice-flow trajectory that crosses BG in East Antarctica, where MODIS imagery shows the presence of an extensive BIA. The mass balance of the firn layer is mainly determined by the SMB. If the SMB is significantly positive, the firn layer grows towards a steady state in which growth at the surface balances with ice formation at the bottom. A low or negative SMB (ablation) leads to a negative firn layer mass balance; if this process continues long enough, the firn layer is completely removed and a BIA forms.

When the RACMO2 simulated SMB is used directly as forcing for the FDM, no BIA on BG is formed. The possible causes are that the $\mathrm{SMB}$ is not negative enough to remove the complete firn layer, or that the simulated firn mass upstream of the BIA is too large. Because RACMO2 assumes the presence of a continuous snow surface across the entire Antarctic ice sheet, certain feedback processes that are characteristic of BIAs are underestimated. Three BIA feedback mechanisms were studied in more detail: (1) increased surface temperature, (2) increased sublimation and (3) decreased accumulation. The increase of surface temperature alone has a minor effect, as it only affects the firn compaction speed, which is of secondary importance for firn mass removal and subsequent $\mathrm{BIA}$ formation. Decreasing the net $\mathrm{SMB}$, by either increasing sublimation or decreasing accumulation, causes a more rapid decrease of firn layer mass. The formation and/or existence of the BG BIA represents the interplay between ice-flow velocity, SMB and firn mass upstream of the ablation area.

Once a BIA has formed, it can be self-sustaining, due to positive feedback mechanisms that remain active as long as the surface is not covered with a continuous layer of fresh snow. As a result, the BIA may persist longer before a new firn layer can establish itself. In our simulations this lag effect was especially important upstream of BG, which, in turn, has a distinct effect on the formation of the BG BIA. Using a moderate combination of the sublimation and accumulation feedback mechanisms, the extent of the observed BG BIA was reasonably well simulated. A robust result is that the sublimation and accumulation effects are of similar importance, while the effect of surface temperature is minor.

\section{ACKNOWLEDGEMENTS}

We acknowledge the Netherlands Polar Program of NWO/ ALW and the ice2sea project, funded by the European Commission's 7th Framework Programme through grant No. 226375, ice2sea manuscript No. 163.

\section{REFERENCES}

Arthern RJ, Vaughan DG, Rankin AM, Mulvaney R and Thomas ER (2010) In situ measurements of Antarctic snow compaction compared with predictions of models. J. Geophys. Res., 115(F3), F03011 (doi: 10.1029/2009JF001306)

Barnola JM, Pimienta P, Raynaud D and Korotkevich Y (1991) $\mathrm{CO}_{2}$ climate relationship as deduced from the Vostok ice core: a reexamination based on new measurements and on a re-evaluation of the air dating. Tellus B, 43(2), 83-90 (doi: 10.1034/ j.1600-0889.1991.t01-1-00002.x)

Bintanja R (1999) On the glaciological, meteorological and climatological significance of Antarctic blue ice areas. Rev. Geophys., 37(3), 337-359 (doi: 10.1029/1999RG900007)

Bintanja R and Van den Broeke MR (1995) The surface energy balance of Antarctic snow and blue ice. J. Appl. Meteorol., 34(4), 902-926 (doi: 10.1175/1520-0450(1995)034<0902:TSE$\mathrm{BOA}>2.0 . \mathrm{CO} ; 2)$

Brown IC and Scambos TA (2004) Satellite monitoring of blue-ice extent near Byrd Glacier, Antarctica. Ann. Glaciol., 39, 223-230 (doi: 10.3189/172756404781813871)

Cassidy WA, Harvey R, Schutt J, Delisle G and Yanai K (1992) The meteorite collection sites of Antarctica. Meteoritics, 27(5), 490-525

Das I and 9 others (2013) Influence of persistent wind scour on the surface mass balance of Antarctica. Nature Geosci., 6(5), 367-371 (doi: 10.1038/ngeo1766)

Frezzotti $M$ and 13 others (2005) Spatial and temporal variability of snow accumulation in East Antarctica from traverse data. J. Glaciol., 51(172), 113-124 (doi: 10.3189/ 172756505781829502)

Herron MM and Langway CC Jr (1980) Firn densification: an empirical model. J. Glaciol., 25(93), 373-385

Lenaerts JTM and Van den Broeke MR (2012) Modeling drifting snow in Antarctica with a regional climate model: 2. Results. J. Geophys. Res., 117(D5), D05109 (doi: 10.1029/2010JD015419)

Lenaerts JTM, Van den Broeke MR, Van de Berg WJ, Van Meijgaard E and Kuipers Munneke P (2012a) A new, highresolution surface mass balance map of Antarctica (1979-2010) based on regional atmospheric climate modeling. Geophys. Res. Lett., 39(4), L04501 (doi: 10.1029/2011GL050713)

Lenaerts JTM and 6 others (2012b) Modeling drifting snow in Antarctica with a regional climate model: 1 . Methods and model evaluation. J. Geophys. Res., 117(D5), D05108 (doi: 10.1029/ 2011JD016145)

Lenaerts JTM, Van den Broeke MR, Scarchilli C and Agosta C (2012c) Impact of model resolution on simulated wind, drifting snow and surface mass balance in Terre Adélie, East Antarctica. J. Glaciol., 58(211), 821-829 (doi: 10.3189/2012JoG12J020)

Ligtenberg SRM, Helsen MM and Van den Broeke MR (2011) An improved semi-empirical model for the densification of Antarctic firn. Cryosphere, 5(4), 809-819 (doi: 10.5194/tc-5-809-2011)

Ligtenberg SRM, Horwath M, Van den Broeke MR and Legrésy B (2012) Quantifying the seasonal 'breathing' of the Antarctic ice sheet. Geophys. Res. Lett., 39(23), L23501 (doi: 10.1029/ 2012GL053628)

Ligtenberg SRM, Van de Berg WJ, Van den Broeke MR, Rae JGL and Van Meijgaard E (2013) Future surface mass balance of the Antarctic ice sheet and its influence on sea level change, simulated by a regional atmospheric climate model. Climate Dyn., 41(3-4), 867-884 (doi: 10.1007/s00382-013-1749-1)

Painter TH, Dozier J, Roberts DA, Davis RE and Green RO (2003) Retrieval of subpixel snow-covered area and grain size from imaging spectrometer data. Remote Sens. Environ., 85(1), 64-77 (doi: 10.1016/S0034-4257(02)00187-6)

Pritchard HD, Ligtenberg SRM, Fricker HA, Vaughan DG, Van den Broeke MR and Padman L (2012) Antarctic ice-sheet loss driven by basal melting of ice shelves. Nature, $\mathbf{4 8 4}(7395)$, 502-505 (doi: 10.1038/nature10968)

Ricchiazzi P, Yang S, Gautier C and Sowle D (1998) SBDART: a research and teaching software tool for plane-parallel radiative 
transfer in the Earth's atmosphere. Bull. Am. Meteorol. Soc., 79(10), 2101-2114

Rignot E, Mouginot J and Scheuchl B (2011) Ice flow of the Antarctic Ice Sheet. Science, 333(6048), 1427-1430 (doi: 10.1126/science.1208336)

Scambos TA, Haran TM, Fahnestock MA, Painter TH and Bohlander J (2007) MODIS-based Mosaic of Antarctica (MOA) data sets: continent-wide surface morphology and snow grain size. Remote Sens. Environ., 111(2-3), 242-257 (doi: 10.1016/ j.rse.2006.12.020)

Scambos TA and 12 others (2012) Extent of low-accumulation 'wind glaze' areas on the East Antarctic Plateau: implications for continental ice mass balance. J. Glaciol., 58(210), 633-647 (doi: 10.3189/2012JoG11J232)

Scarchilli C, Frezzotti M, Grigioni P, De Silvestri L, Agnoletto L and Dolci S (2010) Extraordinary blowing snow transport events in East Antarctica. Climate Dyn., 34(7-8), 1195-1206 (doi: 10.1007/s00382-009-0601-0)

Schytt V (1961) Glaciology II(E). Blue ice-fields, moraine features and glacier fluctuations. In Norwegian-British-Swedish Antarctic Expedition, 1949-52, scientific results IV(E). Norsk Polarinstitutt, Oslo, 181-204

Shepherd A and 46 others (2012) A reconciled estimate of ice-sheet mass balance. Science, 338 (6111), 1183-1189 (doi: 10.1126/ science.1228102)

Sinisalo A and Moore JC (2010) Antarctic blue ice areas - towards extracting palaeoclimate information. Antarct. Sci., 22(2), 99-115 (doi: 10.1017/S0954102009990691)

Spencer MK, Alley RB and Creyts TT (2001) Preliminary firndensification model with 38-site dataset. J. Glaciol., 47(159), 671-676 (doi: 10.3189/172756501781831765)

Stearns LA (2011) Dynamics and mass balance estimates of four large East Antarctic outlet glaciers. Ann. Glaciol., 52(59), 116-126 (doi: 10.3189/172756411799096187)

Swithinbank CWM (1991) Potential airfield sites in Antarctica for wheeled aircraft. CRREL Spec. Rep. 91-24

Takahashi S, Naruse R, Nakawo M and Mae S (1988) A bare ice field in east Queen Maud Land, Antarctica, caused by horizontal divergence of drifting snow. Ann. Glaciol., 11, 156-160

Takahashi S, Endoh T, Azuma N and Meshida S (1992) Bare ice fields developed in the inland part of Antarctica. In Proceedings of the NIPR Symposium on Polar Meteorology and Glaciology, Vol. 5. National Institute of Polar Research, Tokyo, 128-139

Van de Berg WJ, Van den Broeke MR, Reijmer $\mathrm{CH}$ and Van Meijgaard E (2005) Characteristics of the Antarctic surface mass balance, 1958-2002, using a regional atmospheric climate model. Ann. Glaciol., 41, 97-104 (doi: 10.3189/ 172756405781813302)

Van de Berg WJ, Van den Broeke MR, Reijmer $\mathrm{CH}$ and Van Meijgaard E (2006) Reassessment of the Antarctic surface mass balance using calibrated output of a regional atmospheric climate model. J. Geophys. Res., 111(D11), D11104 (doi: 10.1029/2005JD006495)

Van den Broeke MR (1997) Spatial and temporal variation of sublimation on Antarctica: results of a high-resolution general circulation model. J. Geophys. Res., 102(D25), 29765-29777 (doi: 10.1029/97JD01862)

Van den Broeke MR and Bintanja R (1995a) Summertime atmospheric circulation in the vicinity of a blue ice area in east Queen Maud Land, Antarctica. Bound.-Layer Meteorol., 72(45), 411-438

Van den Broeke MR and Bintanja R (1995b) The interaction of katabatic winds and the formation of blue-ice areas in East Antarctica. J. Glaciol., 41(138), 395-407

Van den Broeke MR, Van de Berg WJ, Van Meijgaard E and Reijmer C (2006) Identification of Antarctic ablation areas using a regional atmospheric climate model. J. Geophys. Res., 111(D18), D18110 (doi: 10.1029/2006JD007127)

Van Meijgaard E and 6 others (2008) The KNMI regional atmospheric climate model RACMO version 2.1. (KNMI Technical Report TR302) Royal Netherlands Meteorological Institute (KNMI), De Bilt

Winther J-G, Jespersen MN and Liston GE (2001), Blue-ice areas in Antarctica derived from NOAA AVHRR satellite data. J. Glaciol., 47(157), 325-334

Yoshida M, Ando H, Omoto K and Ageta $Y$ (1971) Discovery of meteorites near Yamato Mountains, East Antarctica. Antarct. Rec., 39, 62-65

Yu J, Liu H, Wang L, Jezek KC and Heo J (2012) Blue ice areas and their topographical properties in the Lambert glacier, Amery Ice shelf system using Landsat ETM+, ICESat laser altimetry and ASTER GDEM data. Antarct. Sci., 24(1), 95-110 (doi: 10.1017/ S0954102011000630) 